\title{
Quadruple Concha Bullosa : A Very Rare Intranasal Turbinate Anatomical Variant
}

\author{
Sang Hoon Lee, $\mathrm{MD}^{1}$, Soo Kweon Koo, $\mathrm{MD}, \mathrm{PhD}^{1}$, Ho Byoung Lee, $\mathrm{MD}^{1}$ and Jong Duk Kim, $\mathrm{MD}^{2}$ \\ ${ }^{1}$ Department of Otolaryngology-Head and Neck Surgery; ${ }^{2}$ Radiology, Busan Saint Mary's Hospital, Busan, Korea
}

\section{- ABSTRACT -}

The nasal turbinates are important structures in the nasal cavity. Pneumatization of the turbinates, also known as concha bullosa, is a common anatomical variant of the nasal cavity. Concha bullosa usually arises from the middle turbinates and rarely in the superior and inferior turbinates. Pneumatization of the uncinate process, also known as an uncinate bulla, is very rare and most cases are asymptomatic, although it may cause nasal obstruction in some cases. Quadruple concha bullosa refers to case of triple concha bullosa (superior, middle, and inferior concha turbinates concha bullosa) accompanied by an uncinate bulla, although this has never been reported. Here, we report a case of quadruple concha bullosa and discuss it along with a review of the literature. (J Clinical Otolaryngol 2017;28:252-255)

KEY WORDS : Anatomy · Turbinates · Tomography $\cdot$ Nasal obstruction.

\section{Introduction}

Nasal turbinate is usually three: Superior, middle, inferior turbinate, but in some cases supreme turbinate is present. On the lateral nasal wall, nasal turbinate takes a roll of maintenance of normal function of nasal cavity including thermoregulation, humidification, lubrication and filtration of inhaled-air through the nasal cavity. ${ }^{11)}$ Pneumatization of the turbinate, also known as concha bullosa, is one of the most common anatomical variations of osteomeatal complex. Most of the concha bullosa occurs in middle turbinate, and rarely in the superior, inferior turbinates. Most of concha bullosa are asymptomatic, but over pneumatized

\footnotetext{
논문접수일 : 2017년 8월 7일

논문수정일 : 2017년 9월 29일

심사완료일 : 2017년 11월 8일

교신저자 : 구수권, 48575 부산광역시 남구 용호로 252번길 23

부산성모병원 이비인후과

전화 : (051) 933-7214·전송 : (051) 956-1956

E-mail:koosookweon@naver.com
}

turbinates may cause nasal obstruction, headache and facial pain. ${ }^{1)}$ A case of triple concha bullosa (pneumatization of superior, middle and inferior turbinate) is extremely rare. ${ }^{2)}$ Uncinate process of ethmoid is a curved bony projection from the ethmoid bone to the ethmoid process of the inferior turbinates. The function of uncinate process is not known but some author writes a paper that the uncinate process is not just a vestigial remnant, but performs a obvious functional role in the ventilatory physiology of the nasal cavity and the paranasal sinuses such as being a barrier and pushing contaminated in-haled air from anterior sinuses. ${ }^{3)}$ Pneumatization of the uncinate process (Uncinate bulla) is very rare anatomic anomaly. Most of uncinate bulla is asymptomatic, but in some cases uncinate bulla can narrowing the middle meatus and infundibulum. And narrowed the middle meatus and infundibulum may cause nasal obstruction and paranasal sinusitis. ${ }^{4)}$ Quadruple concha bullosa refers to a case triple concha bullosa accompanied by uncinate bulla has never ever been reported. Herewith, we report a case of quadruple concha bullosa and discuss it with a review of literature. 
headache.

\section{Case Report}

A-23-years old man was admitted with nasal obstruction and intermittent headache for several years. He denied any history of nasal surgery or medication. Under anterior rhinoscopy and nasal endoscopy, nasal septum was deviated to right and left inferior turbinate was hypertrophied. For further evaluation, non-enhanced computed tomography $(\mathrm{CT})$ of the osteomeatal unit was performed. Coronal osteomeatal CT revealed that pneumatization the inferior, middle and superior turbinate and pneumatized uncinate process of the left side and a nasal septum slightly deviation to the right (Fig. 1, 2). Also, axial osteomeatal CT showed that nasal septum was deviated to left and left inferior turbinate was hypertrophied with pneumatization (Fig. 3, 4). We performed septoplasty, microdebriderassisted inferior turbinoplasty and lateral out-fracture of left inferior turbinate. Three months after surgery, the patient recovered well without complications and did not complain nasal obstruction and intermittent

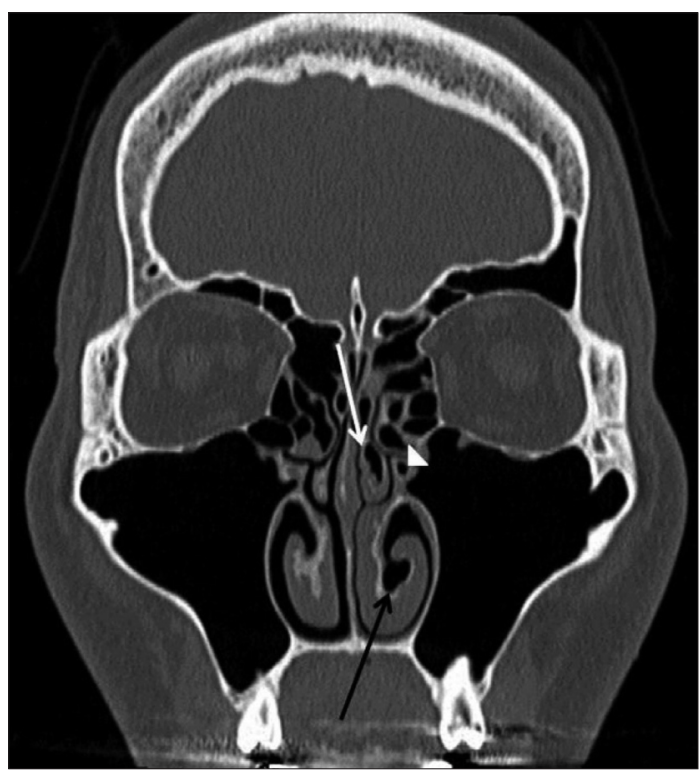

Fig. 1. Coronal CT image of the osteomeatal complex shows the pneumatization of the left middle turbinate (white arrow), left inferior turbinate (black arrow), and left uncinate process (arrowhead).

\section{Discussion}

Anatomical variants of the osteomeatal complex are common in general population. Its incidence is vary-

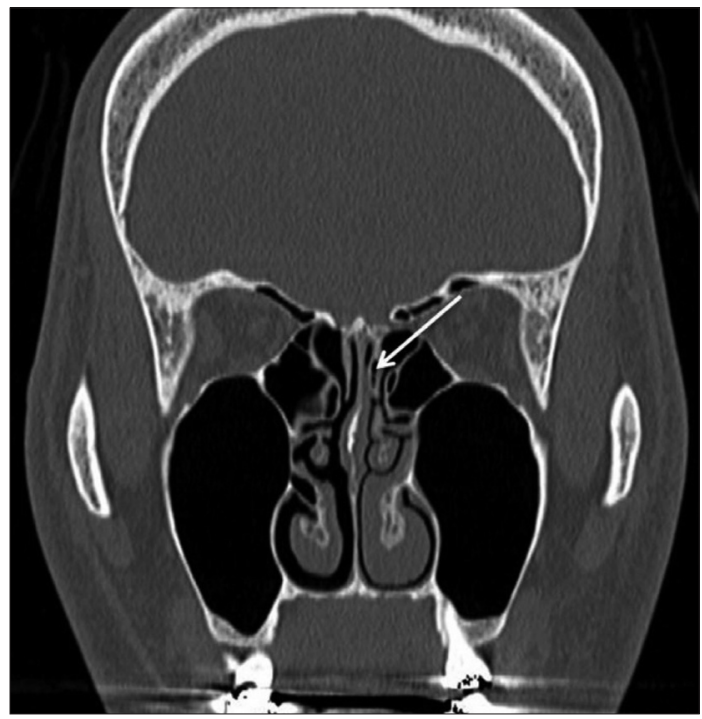

Fig. 2. Coronal CT image of the osteomeatal complex shows the pneumatization of the left superior turbinate (arrow).

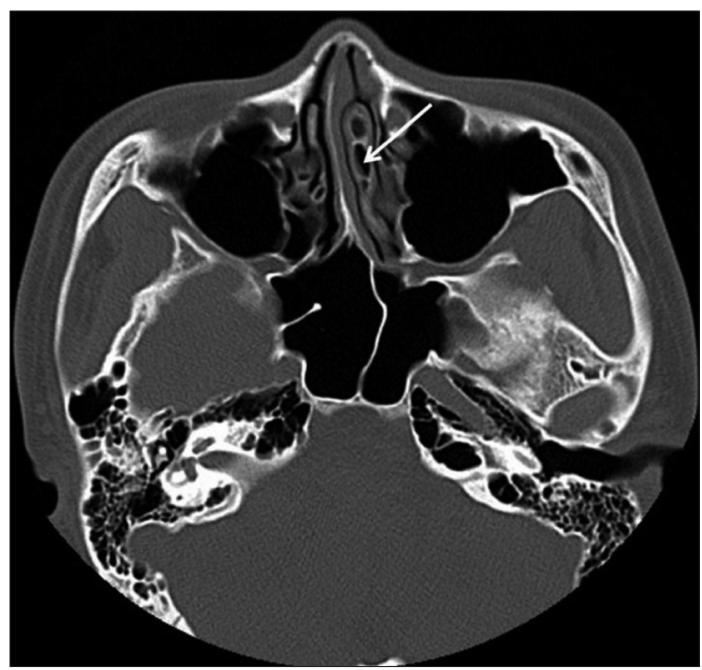

Fig. 3. Axial CT image of the osteomeatal complex shows that the nasal septum is deviated to the right and the pneumatization of the left middle turbinate (arrow). 


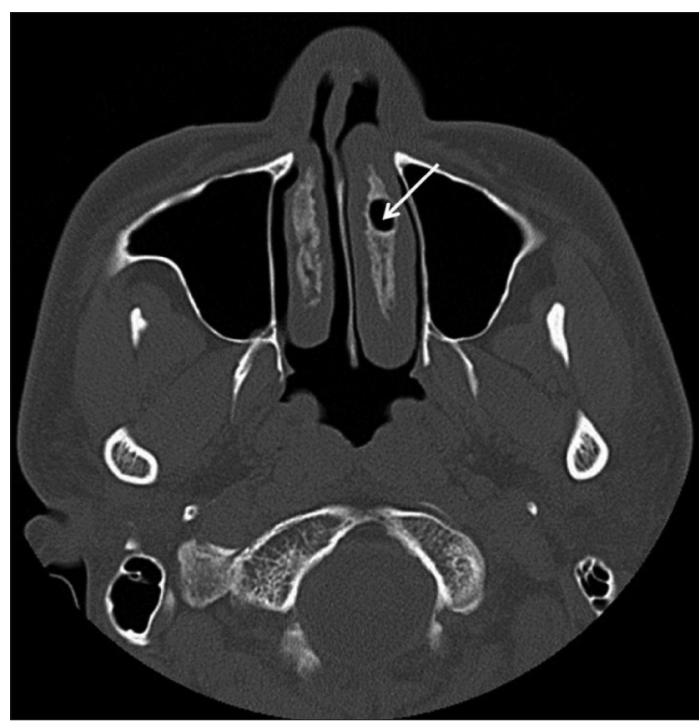

Fig. 4. Axial CT image of the osteomeatal complex shows that the nasal septum is deviated to the right and pneumatization of the left inferior turbinate (arrow).

ing $64.9 \%$ from $93 \%{ }^{5,6)}$ Concha bullosa is the most common anatomical variation of osteomeatal region and its incidence has been reported $13-53 \%$ by various studies. ${ }^{7)}$ Recent developments of image diagnosis including $\mathrm{CT}$ allows easy to detect the anatomical structure and its variation. Getting to the anatomical variations associated with the pathological findings is very useful in diagnostic and therapeutic aspects. We adapted the definition of a concha bullosa as any aeration of the middle turbinate, even if the aeration is restricted to the upper non bulbous portion of the turbinate. ${ }^{7)}$ Coronal view is generally useful to know the anatomical variations, but some cases may need the help of the axial view. In this case, we could diagnose through a coronal view and confirm middle turbinate concha bullosa and inferior turbinate concha bullosa through the axial view.

Although the developmental mechanism of concha bullosa is not still clear, some authors have been suggest several theories. The first is compensatory theory. Stallman et al. suggested that there is a strong relationship between concha bullosa (unilateral or dominant concha bullosa) and nasal septal deviation away from the concha bullosa. ${ }^{7)}$ According to the compensatory theory, the formation of the nasal septal deviation expanding opposite nasal cavity space occurs in the development of concha bullosa. ${ }^{7)}$ Another congenital theory is that concha bullosa is another anatomical variants not correlated with nasal septal deviation, in other word, the nasal septal deviation away from the concha is not the result of the concha pushing the septum. ${ }^{7)}$ Chaitayate et al. ${ }^{8)}$ suggested that genetic factors may have influence on the pneumatization process by using $\mathrm{CT}$ in twins.

Most of concha bullosa are asymptomatic, but the symptoms may be caused by the degree of pneumatization including headache, nasal obstruction and unilateral facial pain, secondary inflammation of concha bullosa. But, relationship between Concha bullosa and sinusitis still debated. ${ }^{9)}$ Treatment is not necessary for cases of asymptomatic case and should only be implemented when concha bullosa is symptomatic. The goals of treatment are to maximize the nasal airway and to minimize the symptoms and complications. The surgical techniques used include out-fracture, crushing and excision of concha bullosa. ${ }^{10)}$ Our cases are associated with nasal septal deviation with inferior turbinate concha bullosa, they cause nasal obstruction and intermittent headache, so we performed surgical treatment such as septoplasty, turbinoplasty and out fracture of inferior turbinate.

\section{REFERENCES}

1) Kantarci M, Karasen RM, Alper F, Onbas O, Okur A, Karaman A. Remarkable anatomic variations in paranasal sinus region and their clinical importance. Eur J Radiol 2004;50(3):296-302.

2) San T, San S, Gürkan E, Erdoğan B. Bilateral triple concha bullosa: a very rare anatomical variation of intranasal turbinates. Case Rep Otolaryngol 2014;851508.

3) Nayak DR, Balakrishnan R, Murty KD. Functional anatomy of the uncinate process and its role in endoscopic sinus surgery. Indian J Otolaryngol Head Neck Surg 2001;53(1): 27-31.

4) Christmas DA, Mirante JP, Yanagisawa E. A pneumatized uncinate process causing obstruction. Ear Nose Throat $J$ 2005;84(12):754.

5) Bolger WE, Butzin CA, Parsons DS. Paranasal sinus bony anatomic variations and mucosal abnormalities: $C T$ 
Sang Hoon Lee, et al : Quadruple Concha Bullosa : A Very Rare Intranasal Turbinate Anatomical Variant

analysis for endoscopic sinus surgery. Laryngoscope 1991; 101(1 Pt 1):56-64.

6) Tonai A, Baba S. Anatomic variations of the bone in sinonasal CT. Acta Otolaryngol Suppl 1996;525:9-13.

7) Stallman JS, Lobo JN, Som PM. The incidence of concha bullosa and its relationship to nasal septal deviation and paranasal sinus disease. AJNR Am J Neuroradiol 2004;25 (9):1613-8.

8) Chaiyasate S, Baron I, Clement P. Analysis of paranasal sinus development and anatomical variations: a CT genetic study in twins. Clin Otolaryngol 2007;32(12):93-7.

9) Nouraei SA, Elisay AR, Dimarco A, Abdi R, Majidi H.
Variations in paranasal sinus anatomy: implications for the pathophysiology of chronic rhinosinusitis and safety of endoscopic sinus surgery. J Otolaryngol Head Neck Surg 2009;38(1):32-7.

10) Koçak İ, Gökler O, Doğan R. Is it effective to use the crushing technique in all types of concha bullosa. Eur Arch Otorhinolaryngol 2016;273(11):3775-81.

11) Jung YS, Kang MK, Kim DY, Jung IH. The effects of the structural changes of inferior turbinate and septal perforation on maxillary sinus ventilation in model experiment. J Clinical Otolaryngol 2003;14(1):92-9. 